\title{
Anomalous abundance and redistribution patterns of rare earth elements in soils of a mining area in Inner Mongolia, China
}

\author{
Lingqing Wang ${ }^{1}$ - Tao Liang ${ }^{1}$
}

Received: 1 December 2015 / Accepted: 25 February 2016 /Published online: 2 March 2016

(C) Springer-Verlag Berlin Heidelberg 2016

\begin{abstract}
The Bayan Obo Mine, the largest rare earth element (REE) deposit ever found in the world, has been mined for nearly 60 years for iron and rare earth elements. To assess the influences of mining activities on geochemical behavior of REEs in soils, 27 surface soil samples and three soil profile samples were collected from different directions in the vicinity of the mine area. The total concentrations of REEs in surface soils varied from 149.75 to $18,891.81 \mathrm{mg} \mathrm{kg}^{-1}$ with an average value of $1906.12 \mathrm{mg} \mathrm{kg}^{-1}$, which was apparently higher than the average values in China $\left(181 \mathrm{mg} \mathrm{kg}^{-1}\right)$. The order of the average concentrations of individual REEs in surface soils was similar to that in Bayan Obo ores, which confirmed that the concentration and distribution of REEs in the soils was influenced by the mining activities. The concentrations of single REE in the soil profiles showed a similar trend with depth with an increase at $0-25 \mathrm{~cm}$ section, then decreased and remained relatively stable in the deep part. The normalized curves inclined to the right side, showing the conspicuous fractionation between the light and heavy REEs, which supported by the North American Shale Composite (NASC) and Post-Archean Australian Shale (PAAS) normalized concentration ratios calculated for selected elements $\left(\mathrm{La}_{N} / \mathrm{Yb}_{N}, \mathrm{La}_{N} /\right.$ $\left.\mathrm{Sm}_{N}, \mathrm{Gd}_{N} / \mathrm{Yb}_{N}\right)$. Slight positive Ce anomaly and negative $\mathrm{Eu}$ anomaly were also observed.
\end{abstract}

\section{Responsible editor: Zhihong Xu}

Lingqing Wang

wanglq@igsnrr.ac.cn

Tao Liang

liangt@igsnrr.ac.cn

1 Key Laboratory of Land Surface Pattern and Simulation, Institute of Geographical Sciences and Natural Resources Research, Chinese Academy of Sciences, Beijing 100101, China
Keywords Rare earth element · Soil · Bayan Obo Mine · Enrichment $\cdot$ Mining activities

\section{Introduction}

Rare earth elements (REEs) are a group of 15 elements of which only promethium $(\mathrm{Pm})$ does not occur naturally in the Earth's crust (Liang et al. 2014). REEs share similar chemical and physical properties and tend to exist together naturally rather than in isolation, which explains their very similar behavior in the environment (Tyler 2004; Wang et al. 2011). REEs can be divided into two groups by their atomic number and masses - light REEs (LREEs) from La to Eu and heavy REEs (HREEs) from Gd to Lu. The REE abundance in the Earth's crust varies from $0.5 \mathrm{mg} \mathrm{kg}^{-1}(\mathrm{Tm})$ to $66 \mathrm{mg} \mathrm{kg}^{-1}$ (Ce) with a mean of about $215 \mathrm{mg} \mathrm{kg}^{-1}$ for total REEs (Tyler 2004).

Human activities such as mining and construction activities can significantly disturb the natural flow of elements between major ecosystem reservoirs and alter the physical and chemical processes at the Earth's surface (Sen and Peucker-Ehrenbrink 2012). It is widely recognized that mining activities for rare earth ores have changed the environmental conditions, causing serious environmental problems such as permanent damages to ecosystems, severe soil erosion, air pollution, and loss of biodiversity (Salomons 1995; Aguilar et al. 2004). Meanwhile, the large-scale and rapid increases of the exploitation activities of REE resources have resulted in substantial increases of REE levels in soils around the mining area. Rare earth elements exist in a variety of minerals distributed in a wide variety of mineral classes including halides, carbonates, oxides, phosphates, and silicates (Jordens et al. 2013; Liang et al. 2014). Generally, low concentrations of REEs are found in environment and they can accumulate following anthropogenic inputs because of the low mobility of these elements (Cao et al. 2000). Rare earth 
element abundances in soils around the mining areas are influenced by their parent materials, texture, weathering history and pedogenic processes, organic matter contents and reactivity, and anthropogenic disturbances (Aubert et al. 2002; Tyler 2004; Morgan et al. 2012).

Rare earths are widely used for traditional sectors including metallurgy, petroleum, textiles, and agriculture, and they are also becoming indispensable and critical in many high-tech industries such as electronic products, green energy, and aerospace alloys (Brioschi et al. 2013). The global demand for REEs is growing at a rate of 3.7-8.6\% annually (Tan et al. 2015). In 2011 , China produced over $90 \%$ of the world's rare earth supply with only $23 \%$ of the world total reserves (Anonymous 2012). Due to the continuous exploitation of rare earths minerals, the percentage of China's rare earth reserve in the world has been steadily decreasing from $75 \%$ in 1970 to $23 \%$ in 2011 (Chen 2011; Anonymous 2012). The presence of excessive REEs in soils may act as pollutants causing serious consequences for surrounding ecosystems, groundwater, agricultural productivity, and human health (Li et al. 2013). Studies have indicated the harmful effects and health hazards of REEs to human beings; for example, the long-term exposure of REE dust may cause pneumoconiosis in humans (Hirano and Suzuki 1996).

REEs have caused widespread concern because of their similar chemical behavior (Wang et al. 2011; Liang et al. 2014), their persistence and environmental behavior (Aubert et al. 2002; Laveuf and Cornu 2009; Agnan et al. 2014), and chronic toxicity (Brioschi et al. 2013; Li et al. 2013). However, there is still lack of knowledge of REE accumulation and ecological effects in soils around the rare earth mining areas. The Bayan Obo REE-Nb-Fe Mine is the largest currently existing REE deposit, which was discovered in 1927 and started the production of rare earths in 1957. Bayan Obo Mine is a surface mine and open-pit methods are used. REEs are extracted from the minerals as a by-product of iron ore extraction. Outdated production processes and techniques in the mining, dressing, smelting, and separating of rare earth have severely damaged surface vegetation; caused soil erosion, pollution, and acidification; and reduced or even eliminated crop output. In this study, REE distribution in soils around the Bayan Obo Mine has been investigated to assess their pollution levels caused by the mining activities. The results will provide scientific evidence for evaluating the ecological risks associated with the exploitation of rare earth minerals and preventing REE pollution in soils and eco-resumption.

\section{Materials and methods}

\section{Study area}

The Bayan Obo Fe-REE-Nb Mine ( $\left.109^{\circ} 59^{\prime} \mathrm{E}, 41^{\circ} 48^{\prime} \mathrm{N}\right)$ in Inner Mongolia is the world's largest REE deposit. It is located in the northern margin of the North China Craton, and hosted in the Mesoproterozoic Bayan Obo Group (Sun et al. 2013). The Bayan Obo region has a semi-arid, temperate, and continental monsoon climate. The mean annual temperature is $2.4^{\circ} \mathrm{C}$ ranging from $-16.2^{\circ} \mathrm{C}$ in January to $19.4^{\circ} \mathrm{C}$ in July. The average annual precipitation is about $240-400 \mathrm{~mm}$, and evaporation is $2100-2700 \mathrm{~mm}$. The prevailing wind direction is northwest. The average annual wind speed is $5.5 \mathrm{~m} / \mathrm{s}$ and the average number of days with strong wind is 70 days per year.

The most prominent feature of the Bayan Obo Mine is that the ore-bearing dolomite marbles, which extend about $16 \mathrm{~km}$ long from west to east and are 1-3 km wide, contain remarkably high concentrations of REEs. REEs occur dominantly as monazite and bastnasite, but more than 20 REEs-containing minerals and 15 niobium minerals have been reported (Wu 2008). Their total reserves have been estimated as at least 1.5 billion tons of iron (average grade $35 \%$ ), at least $48 \mathrm{Mt}$ of REOs (average grade $6 \%$ ), and about $1 \mathrm{Mt}$ of niobium (average grade $0.13 \%$ ) (Drew et al. 1990). The Bayan Obo Mine produced 55,300 $\mathrm{t}$ of $\mathrm{RE}_{2} \mathrm{O}_{3}$ in 2005, accounting for $47 \%$ of the total rare earth production of China and $45 \%$ of that of the world ( $\mathrm{Wu} 2008$ ). The dolomite marble contains many iron ore bodies, scattering from west to east and occurring as large lens or beds as individual ones. They may be divided into three portions. The biggest ones are the main ore body and the eastern ore body (Fig. 1), each of which include iron-REE resources with more than $1000 \mathrm{~m}$ of strike length and average 5.41 and $5.18 \%$ rare earth oxides (REOs), respectively (Yuan et al. 1992). The Western ore body is composed of many small sub-ore bodies with exploitations on a small scale (Xu et al. 2008).

\section{Sampling and measurement}

Surface soil samples were collected at a depth of $0-10 \mathrm{~cm}$ at 27 sites located in the vicinity of the Bayan Obo Mine (Fig. 1). According to the position of the mining area and prevailing wind direction, these sites were divided into four areas: southeast (labeled An, $n=1,2, \ldots, 8$ ); southwest (labeled Bn, $n=1$, $2, \ldots, 8$ ); northwest (labeled Cn, $n=1,2, \ldots, 5$ ); and northeast (labeled Dn, $n=1,2, \ldots, 6)$. Three soil profiles (labeled Pn, $n=1,2,3)$ up to a depth of $70 \mathrm{~cm}$ were also selected to reveal the vertical distribution of REEs. A total of 11 sections at depths of $0-3,3-6,6-9,9-12,12-15,15-20,20-25,25-$ $30,30-40,40-50$, and 50-70 cm were taken from each soil profile. All samples were stored in a portable cryostat and transported to the laboratory. The collected soil samples were frozen-dried and sieved through a 100-mesh sieve to remove large debris, stones, and pebbles prior to analysis. The main soil type is chestnut soil (Haplic Krastazem, FAO) in the Bayan Obo area and it has a $\mathrm{pH}$ value of 7.8 , organic matter 


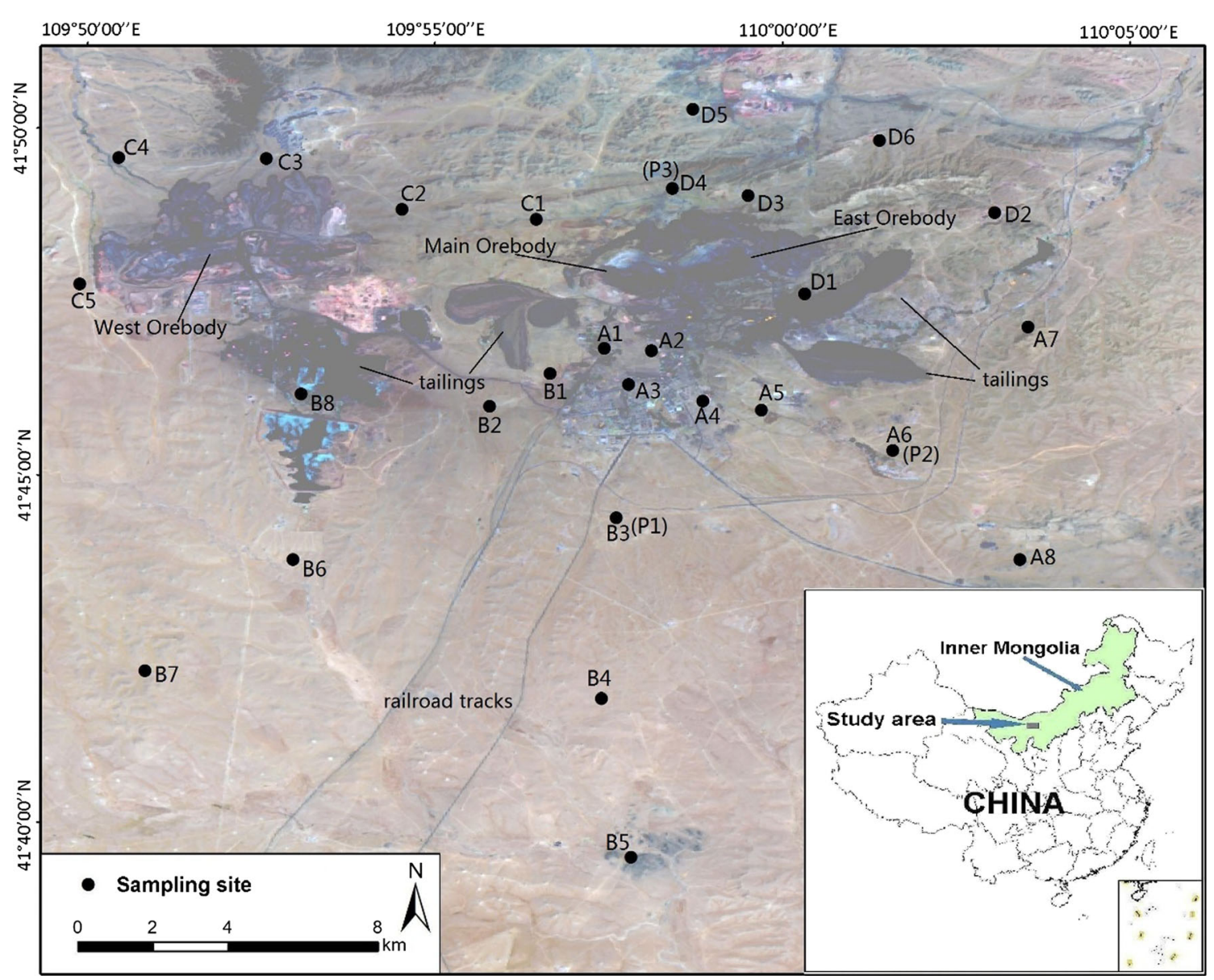

Fig. 1 Map of the study area and sampling sites

content of $2.03 \%$, total $\mathrm{P}$ and Olsen $\mathrm{P}$ of 722.61 and $27.656 \mathrm{mg} \mathrm{kg}^{-1}$, respectively.

Soil samples $(0.05 \mathrm{~g})$ were digested in a mixture of $3 \mathrm{ml} \mathrm{HNO}_{3}, 0.5 \mathrm{ml} \mathrm{HClO}_{4}$, and $6 \mathrm{ml} \mathrm{HF}$ in a sealed Teflon vessel on hotplate at $200{ }^{\circ} \mathrm{C}$ for $8 \mathrm{~h}$. The digested solution was evaporated to near dryness. The residue was dissolved by $2 \% \mathrm{HNO}_{3}$ and transferred into a $50-\mathrm{ml}$ flask, then diluted to volume with deionized water. The blank and duplicate digest were carried out in the same way. REE concentrations in the digested solutions were measured using inductively coupled plasma mass spectrometry (ICP-MS, ELAN DRC-e, Perkin Elmer SCIEX) (Wang et al. 2011). The detection limit of ICP-MS is $1 \mathrm{ng} \mathrm{l}^{-1}$. All measurements were carried out in duplicate. The quality control was achieved using certified reference samples GBW07303 from the National Research Center for Certified Reference Materials (Beijing, China). The results for the reference samples were in line with the reference values, with the deviations less than $5 \%$.

Enrichment factor (EF) was calculated based on the normalization of analytical data against the reference element and widely used to estimate the anthropogenic impact on soils
(Sutherland 2000; Loska et al. 2004; Tang et al. 2010). The $\mathrm{EF}$ is defined by the following formula:

$$
\mathrm{EF}=\left(C_{i} / C_{r}\right)_{\text {sample }} /\left(C_{i} / C_{r}\right)_{\text {crust }}
$$

where $C_{i}$ is the concentration of the element considered in the studied samples or the crust, and $C_{r}$ is the concentration of reference element in the studied samples or the crust. A reference element should not be influenced by anthropic activities and should be little affected by weathering processes. The most common reference elements used in literature are $\mathrm{Al}, \mathrm{Ca}, \mathrm{Fe}, \mathrm{Li}, \mathrm{Mn}, \mathrm{Sc}$, and Sr (Sutherland 2000; Tang et al. 2010). In this study, Al was used as a conservative element to calculate the EFs of REEs. Contents of REEs and $\mathrm{Al}$ in the upper continental crust were taken from McLennan (2001). Contamination categories can be identified on the basis of the enrichment factor. A result of $\mathrm{EF}<2$ indicates deficiency to minimal enrichment, $2<\mathrm{EF} \leq 5$ means moderate enrichment, $5<\mathrm{EF} \leq 20$ means significant enrichment, $20<\mathrm{EF} \leq 40$ signifies very high enrichment, and EF $>40$ means extremely high enrichment (Sutherland 2000). 


\section{Results and discussion}

\section{Descriptive statistics of REE concentrations in soils}

The basic statistics of REE concentrations in the surface soil samples were summarized in Table 1 . The coefficients of variation $(\mathrm{CVs})$ of $\mathrm{La}, \mathrm{Ce}, \mathrm{Pr}, \mathrm{Nd}, \mathrm{Sm}, \mathrm{Eu}$, and $\mathrm{Gd}$ were greater than $100 \%$, showing strong variability. The variability of $\mathrm{Tb}$, Dy, Ho, Er, Tm, Yb, and Lu was moderate with the CV fluctuated from 24.1 to $95.4 \%$. Low CV values indicated a spatially homogeneous distribution of REE concentrations, whereas high $\mathrm{CV}$ values indicated a non-homogenous surface distribution in the study area (Karanlik et al. 2011).

The Kolmogorov-Smirnov (K-S) test was applied to determine if the data followed a normal distribution. The results indicated that REE concentrations were not normally distributed $(p<0.05)$ except for $\mathrm{Er}, \mathrm{Tm}, \mathrm{Yb}$, and $\mathrm{Lu}$. As a result, the geometric mean or the transformed mean (log transformed or Box-Cox transformed) are used to describe average concentrations (McGrath et al. 2004). In the present study, following a Box-cox transformation, all the data successfully passed the K-S test for normality.

Strong variation was observed in the total REE concentrations among the surface soil samples around the Bayan Obo region, which varied from 149.75 to $18,891.81 \mathrm{mg} \mathrm{kg}^{-1}$ with an average value of $1906.12 \mathrm{mg} \mathrm{kg}^{-1}$. The sum of all REEs ( $\sum$ REE) in the study was much higher than those reported by $\mathrm{Hu}$ et al. (2006) with a mean REE concentration in China of $181 \mathrm{mg} \mathrm{kg}^{-1}$ (1225 soil samples), and it was also higher than the background values of soils in the Bayan Obo region $(\mathrm{Li}$ et al. 2010). Other authors have found slightly lower concentrations of REEs in Japan $\left(98 \mathrm{mg} \mathrm{kg}^{-1}\right.$, Yoshida et al. 1998); Australia (105 mg kg${ }^{-1}$, Diatloff et al. 1996); and Germany (305 mg kg${ }^{-1}$, Loell et al. 2011). The arithmetic means, geometric means (GMs), and medians of REEs in the surface soils are higher than their background values in soils of Bayan Obo region (CNEMC 1990).

Results from the present study revealed a highly variable concentration of individual REEs, in the following decreasing order: $\mathrm{Ce}>\mathrm{La}>\mathrm{Nd}>\mathrm{Pr}>\mathrm{Sm}>\mathrm{Gd}>\mathrm{Dy}>\mathrm{Er}>\mathrm{Yb}>\mathrm{Eu}>$ $\mathrm{Tb}>\mathrm{Ho}>\mathrm{Tm}>\mathrm{Lu}$. The sequence was similar to that in Bayan Obo ores, determined in 2012 (Xu et al. 2012), and similar to the order of REEs in the sediments (Zhu et al. 1997), animal, plant, environmental, and geological samples (Wang et al. 1995). The concentrations of LREEs accounted for the main part with $83 \sim 95 \%$ of the total, while cerium accounted for $48 \%$. Similar trend was observed in the Bayan Obo ores, which indicated that the concentration and distribution of individual REE was influenced by the mining activities. The concentrations of single REEs conformed to the distribution law of odd-even numbers (Wang et al. 2011). Meanwhile, there is a statistically significant correlation $\left(R^{2}>0.89 ; p<0.05\right)$ between all the elements examined. This suggests a similar source of these elements caused by the rare earth mining. Previous studies have reported that REEs can continuously accumulate in surface soils following various pathways such as atmospheric deposition (Tyler 2004), mining activities (Zhang et al. 2000), and application of REE fertilizers (Pan et al. 2002) because of the low mobility of these elements. Results in the present study suggest that soil environment in Bayan Obo mining area was seriously polluted from the industries involving rare earth exploitation and

Table 1 Descriptive statistics of REE concentrations $\left(\mathrm{mg} \mathrm{kg}^{-1}\right)$ in surface soils

\begin{tabular}{llllllllllll}
\hline & Mean & SD & CV $(\%)$ & Min & Max & GM & $Q 1$ & $Q 2$ & $Q 3$ & Background value $^{\mathrm{a}}$ & K-S $p$ \\
\hline $\mathrm{La}$ & 518.14 & 1101.49 & 212.6 & 33.82 & 5421.58 & 173.82 & 72.17 & 114.54 & 387.73 & 32.8 & 0.005 \\
$\mathrm{Ce}$ & 982.78 & 1828.20 & 186.0 & 59.59 & 8841.18 & 352.15 & 131.44 & 185.28 & 989.43 & 49.1 & \\
$\mathrm{Pr}$ & 88.81 & 217.45 & 244.9 & 7.72 & 1035.59 & 30.09 & 15.44 & 20.65 & 52.14 & 5.68 & 0.012 \\
$\mathrm{Nd}$ & 262.63 & 641.01 & 244.1 & 27.97 & 3332.80 & 106.20 & 57.52 & 77.54 & 194.88 & 19.2 & 0.001 \\
$\mathrm{Sm}$ & 20.77 & 26.10 & 125.7 & 5.01 & 118.47 & 13.97 & 8.93 & 11.07 & 20.52 & 3.81 & 0.001 \\
$\mathrm{Eu}$ & 2.11 & 0.73 & 34.7 & 1.06 & 3.39 & 1.99 & 1.44 & 1.90 & 2.64 & 0.81 & 0.023 \\
$\mathrm{Gd}$ & 15.43 & 18.91 & 122.5 & 4.60 & 92.86 & 10.94 & 7.08 & 9.11 & 15.34 & 3.47 & 0.009 \\
$\mathrm{~Tb}$ & 1.46 & 1.40 & 95.4 & 0.58 & 6.99 & 1.17 & 0.80 & 0.99 & 1.47 & 0.47 & 0.003 \\
$\mathrm{Dy}$ & 6.37 & 4.20 & 65.9 & 3.15 & 22.23 & 5.61 & 4.28 & 5.03 & 6.24 & 3.05 & 0.006 \\
$\mathrm{Ho}$ & 1.04 & 0.48 & 45.7 & 0.62 & 2.72 & 0.97 & 0.81 & 0.89 & 1.11 & 0.66 & 0.014 \\
$\mathrm{Er}$ & 3.29 & 1.72 & 52.2 & 1.87 & 9.72 & 3.02 & 2.40 & 2.60 & 3.45 & 1.82 & 0.034 \\
$\mathrm{Tm}$ & 0.38 & 0.09 & 24.1 & 0.26 & 0.63 & 0.37 & 0.31 & 0.36 & 0.41 & 0.27 & 0.058 \\
$\mathrm{Yb}$ & 2.56 & 0.62 & 24.1 & 1.70 & 4.09 & 2.50 & 2.19 & 2.36 & 2.70 & 1.79 & 0.477 \\
$\mathrm{Lu}$ & 0.35 & 0.05 & 13.2 & 0.27 & 0.42 & 0.35 & 0.33 & 0.35 & 0.38 & 0.27 \\
$\mathrm{KREE}$ & 1906.12 & 3804.00 & 199.6 & 149.75 & $18,891.81$ & 727.79 & 310.55 & 433.24 & 1726.71 & 123.2 \\
\hline
\end{tabular}

$S D$ standard deviation, $C V$ coefficient of variation, $G M$ geometric mean, $Q 1$ first quartile, $Q 2$ median, $Q 3$ third quartile

${ }^{a}$ CNEMC (China National Environmental Monitoring Center), 1990 
production. A vast majority of the exogenous REEs are fixed on solid surfaces and exist in inert forms, which are normally concentrated in the top layer of soils around the mining areas. Meanwhile, results of the present study revealed that the distribution patterns of REEs in soils are all in line with their parent rocks. No obvious fractionation between REEs occurred during those transport processes.

\section{Spatial distribution of REEs in surface soils}

The experimental semivariogram of $\Sigma$ REE concentrations could be fitted with a spherical model with parameters: nugget effect $\left(C_{0}\right) 1000 \mathrm{mg}^{2} / \mathrm{kg}^{2 ;}$ sill $\left(C_{0}+C\right) 16,910,000 \mathrm{mg}^{2} / \mathrm{kg}^{2}$; and range $3900 \mathrm{~m}$. The ratio of nugget effect $\left(C_{0}\right)$ over sill $\left(C_{0}+C\right), r=C_{0} /$ $\left(C_{0}+C\right)$, can be used to express spatial correlations of REEs and provide a quantitative basis for estimating points at unsampled locations. If the ratio did not exceed $25 \%$, the REE concentrations were considered strongly spatially dependent; if the ratio was between 25 and $75 \%$, the concentration was considered moderately spatially dependent; and if the ratio was greater than $75 \%$, the concentration was considered weakly spatially dependent (Xie et al. 2012). In the present study, the ratio was smaller than $25 \%$, showing strong spatial dependence.

The spatial distribution of $\Sigma$ REE concentrations is a useful aid to assess the possible sources of enrichment and to identify hotspots with high REE concentrations. The estimated map of REEs in soil is shown in Fig. 2. Several areas with high levels of REE concentration were identified around the mining site in the map. REE concentrations were found to be highly concentrated in the vicinity of the eastern ore and west ore areas and decreased with the distance away from the central region of mining area. This shows that the mining-milling operations and disposal of tailings can contribute significantly to REE accumulation in surface soils. It also showed a geographical trend, with high REE concentrations in the southeastern area, which could be caused by the strong northwesterly winds prevailed in this region. Wind erosion can be a major cause of the loss and dispersion of material from tailings impoundments into their surroundings because of the low precipitation and high evaporation rates in the semi-arid climate areas (Razo et al. 2004). Under natural conditions, the translocation ability of REEs is relatively weak as compared with other metal ions (Liang et al. 2014). A vast majority of the exogenous REEs are fixed on solid surfaces and exist in inert forms, which are normally concentrated in the top layer of soils around the mining area. It should also be noted that the high REE concentration areas were generally found along the railway. This may be attributed to the diffusion of rare earth mineral powder during transportation process of rare earth minerals and tailings.

The average EF of the total REEs in the Southeast was higher than 40, confirming the extremely high level of contamination of REEs in soils in this part; while the total REE in the southwest and northeast directions, with the average EFs between 5 and 20, were classified as significant enrichment. The average EF of the total REEs in the northwest was relatively low and ranged between 2 and 5, indicating moderate
Fig. 2 Estimated map of REEs concentration in surface soils around the mining area

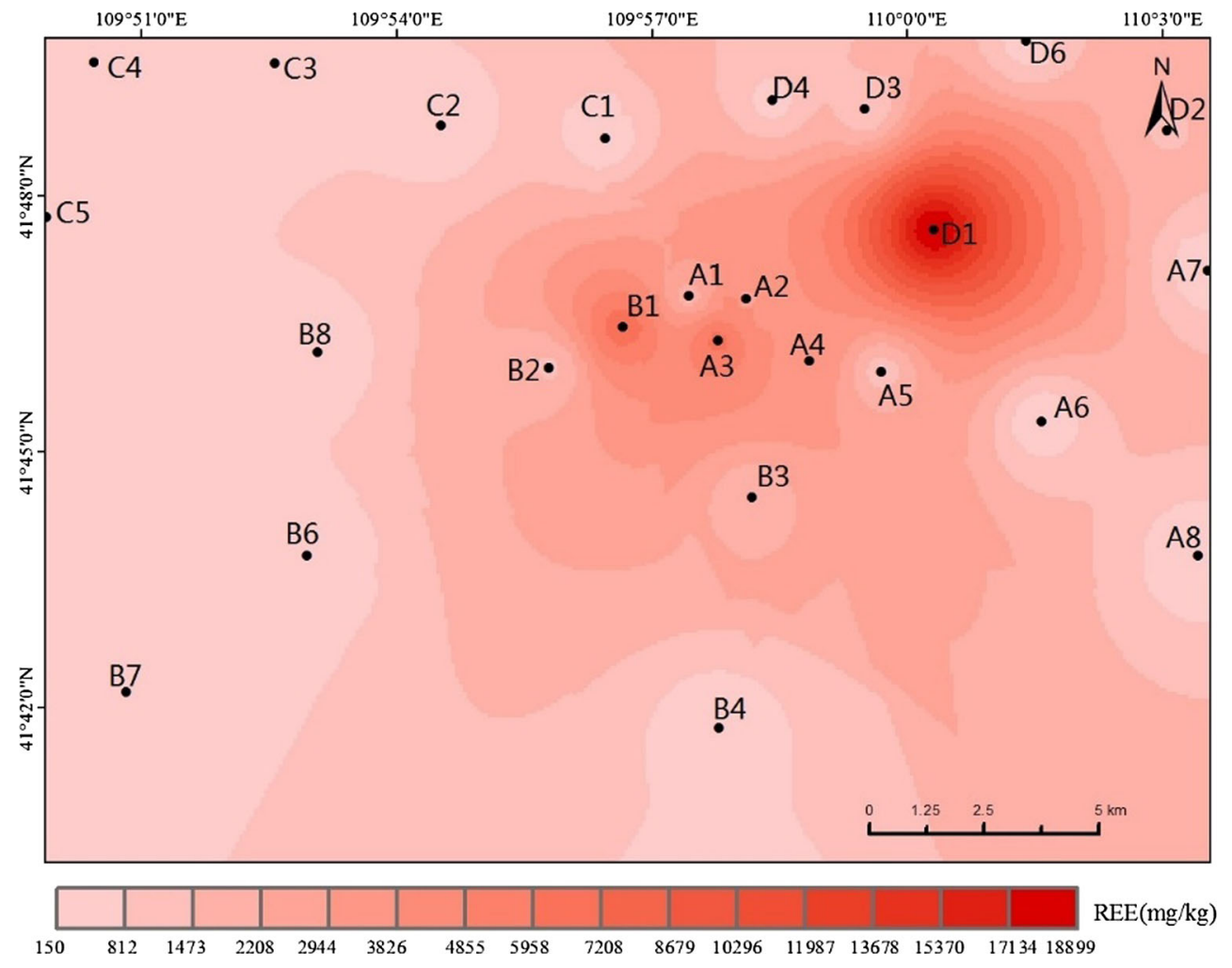


enrichment. For the single REE, EFs can also be an effective tool to differentiate a natural origin from anthropogenic sources in this study. Mean values of EFs for La and Ce in southeast directions were higher than 40 , while Pr and $\mathrm{Nd}$ had average EFs close to 40, indicating extremely high contamination of soils in these parts. Mean EFs ranged between 5 and 20 for $\mathrm{La}, \mathrm{Ce}, \mathrm{Pr}$, and $\mathrm{Nd}$ in the southwest and northeast directions implying significant influences of non-crustal sources. Most of the HREEs, such as Ho, Er, Tm, Yb, and $\mathrm{Lu}$, had mean EFs less than 2, reflecting the lack of contamination with these elements. The EF analysis confirms that REEs enriched in the soils with varying levels, which was caused by anthropogenic sources and influenced by the prevailing wind in this region.

\section{Vertical distribution of REEs in soils}

The vertical distributions of REEs in three soil profiles from different locations in the Bayan Obo Mine area are shown in Fig. 3. The total concentrations of REEs in the three profiles were different, with a minimum of $744.75,874.96$, and $1573.34 \mathrm{mg} \mathrm{kg}^{-1}$; a maximum of $1416.87,1319.24$, and
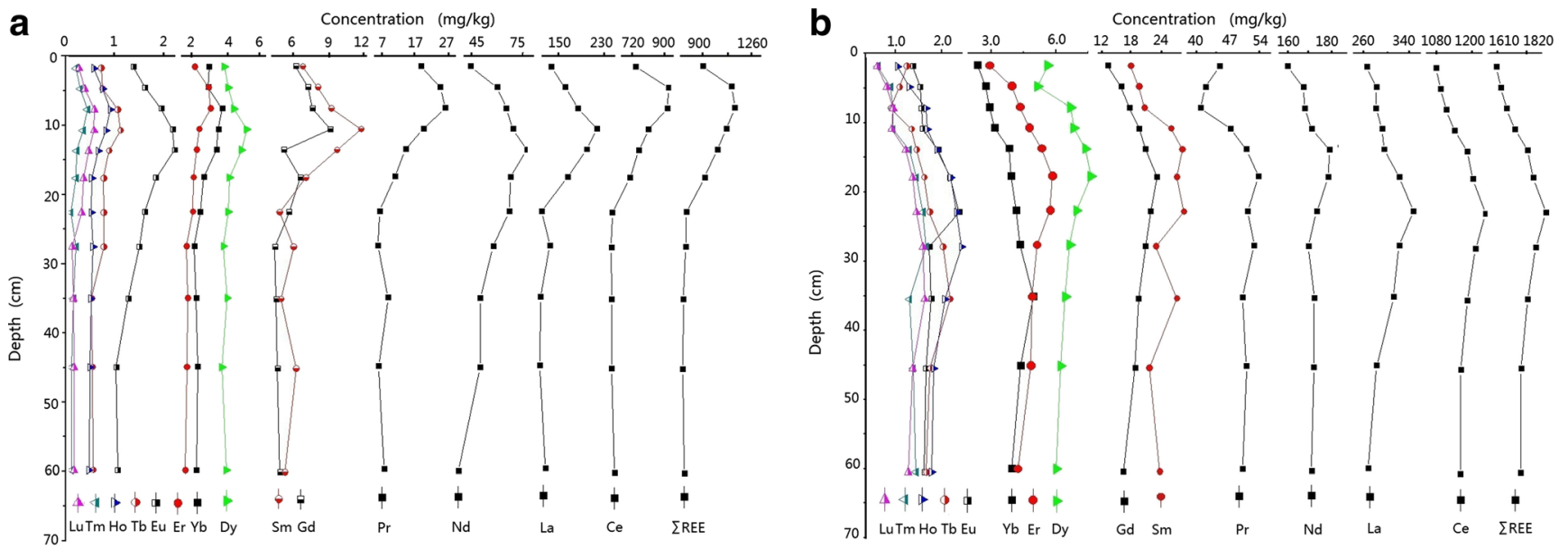

$1913.99 \mathrm{mg} \mathrm{kg}^{-1}$; and a mean of $1145.58,1319.24$, and $1740.46 \mathrm{mg} \mathrm{kg}^{-1}$, respectively. The distribution curves of the total REE concentrations in the three profiles were also different in pattern: The total REE concentration of soil profile $\mathrm{P} 1$ increased with increasing depth from the surface to $10 \mathrm{~cm}$ then decreased and remained relatively constant below a depth of $20 \mathrm{~cm}$ (Fig. 3a). The total REE concentration of the whole profile $\mathrm{P} 2$ was high and particularly elevated at $0-25 \mathrm{~cm} \mathrm{sec}-$ tion, with a maximum at $20-25 \mathrm{~cm}$ in depth (Fig. 3b). The total REE concentration of profile $\mathrm{P} 3$ was significantly elevated at $0-10 \mathrm{~cm}$ and maintained stability at $10-20 \mathrm{~cm}$ section, but decreased significantly below a depth of $30 \mathrm{~cm}$ (Fig. 3c). Figure 4 shows cumulative frequency distribution of REEs EF in the soil profiles. The mean value of EF for the total REE was 12.05 (ranging between 7.06 and 17.33), indicating a significant enrichment of REEs in the soil profiles around the mining area.

The concentrations of single REEs showed a roughly similar trend with depth, which increased at $0-25 \mathrm{~cm}$ section, decreased, and remained relatively constant in the deeper part $(>25 \mathrm{~cm})$. The $\mathrm{EF}$ values for $\mathrm{La}$ and $\mathrm{Ce}$ in all the soil profiles were $>5$, indicating that they were significantly enriched in the

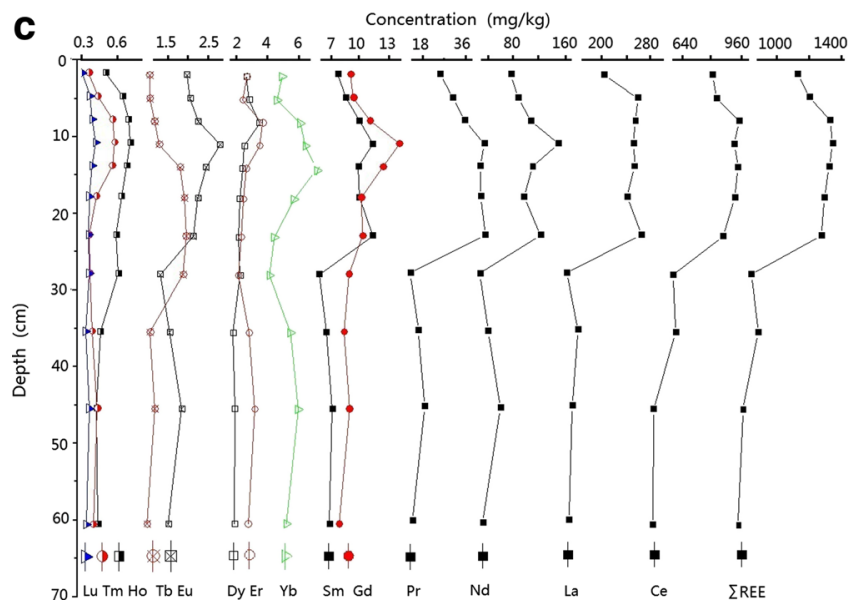

Fig. 3 Vertical distributions of REEs in three soil profiles (P1 (a); P2 (b); P3 (c)) from the different locations in Bayan Obo mining area 

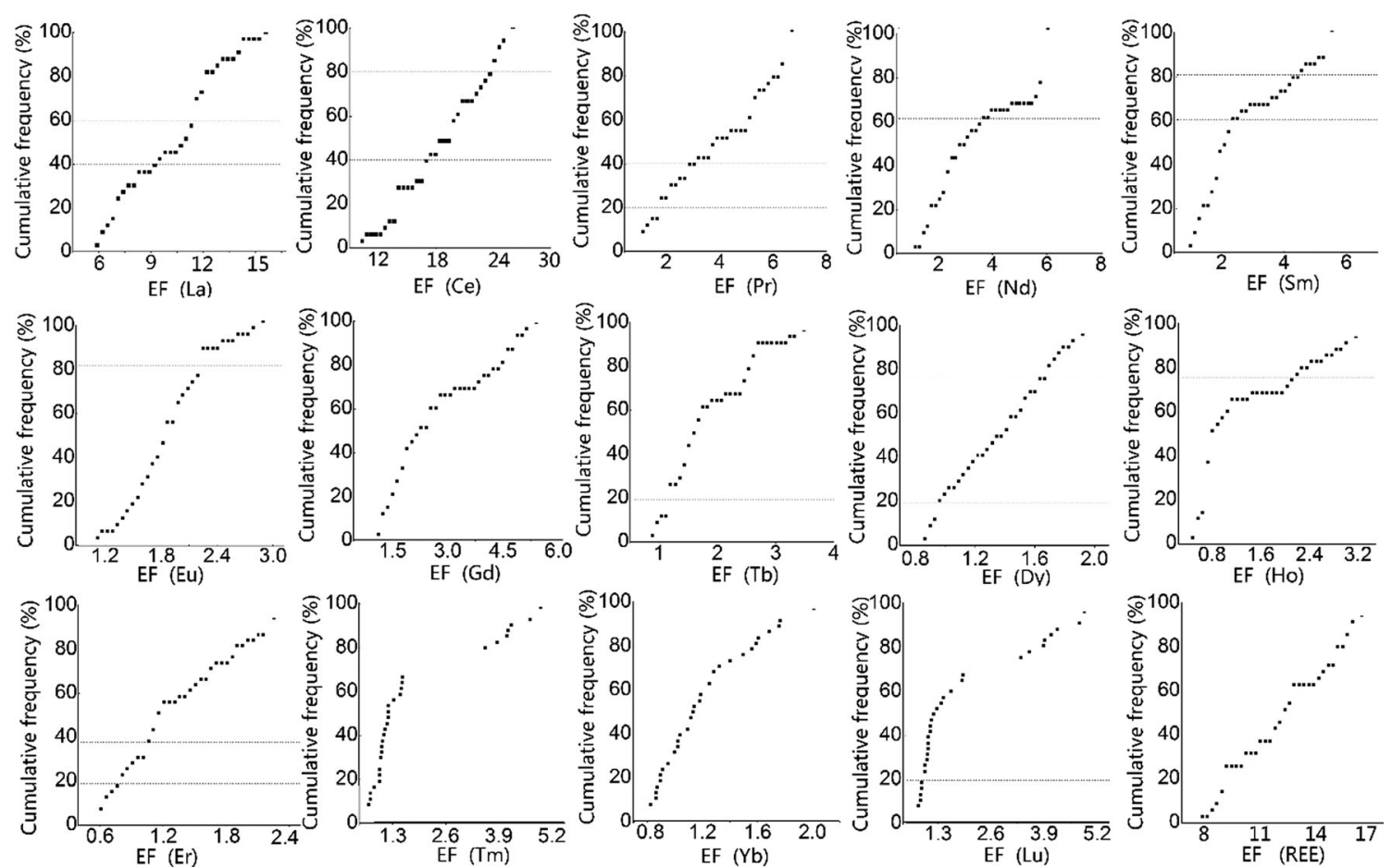

Fig. 4 Cumulative frequency distribution of EF of REEs in the soil profiles

soil profiles. The EF values for $\operatorname{Pr}$ in $76 \%$, Nd in $77 \%$, Sm in $53 \%$, and $\mathrm{Gd}$ in $55 \%$ in $2-5$ reveal that these elements in most of the soil profiles correspond to moderate enrichment. The EF values of Dy in all soil profiles samples, Eu in $63 \%$, $\mathrm{Tb}$ in $66 \%$, Tm in $68 \%$, Ho in $73 \%$, Er in $86 \%$, Yb in $95 \%$, and $\mathrm{Lu}$ in $71 \%$ were $<2$, revealing that these elements in most of the soil profiles corresponded to minimal enrichment. The enrichment and fluctuation of REE in soil profiles is mainly attributed to the historical pollution from mining area and anthropogenic disturbance.

\section{Shale-normalized REE patterns}

To eliminate the Oddo-Harkins effect and characterize the REE patterns of soils, the estimated average composition of REEs in the North American Shale Composite (NASC) and Post-Archean Australian Shale (PAAS) (McLennan 2001) were selected to normalize the measured REE concentrations (Fig. 5).

It can be found that the two shale-normalized REE distribution patterns for soil were generally identical. The REE patterns were characterized by LREE enrichment and HREE depletion, with the curves extending downward from the left to the right. The ratio of $\mathrm{La}_{N} / \mathrm{Yb}_{N}$ was used to represent the inclination of the shale-normalized curves. When the ratio of $\mathrm{La}_{N} / \mathrm{Yb}_{N}$ is greater than or equal to 1 , the curves of LREE incline to the right side, suggesting the soil is rich in LREE and deficient in HREE. The ratio of $\mathrm{La}_{N} / \mathrm{Yb}_{N}$ in the present study was $6.97_{\mathrm{NASC}}$ and $4.70_{\mathrm{PAAS}}$ (Table 2). This means that the soil samples around the rare earth ores belonged to a light REE soil type intensified by the mineral exploitation. Generally, higher concentrations of LREE were observed in soils developed on phosphate and carbonate rocks, whereas the basalt-weathered soils showed enrichment in HREE (Chen and Yang 2010).

The distribution patterns of REEs in soil are characterized by obvious fractionation of LREE and HREE. The LREEs were more abundant in the soil samples and the LREE/HREE ratio was 27.32. The normalized $\mathrm{LREE}_{N} /$ $\mathrm{HREE}_{N}$ ratio was $3.93_{\mathrm{NASC}}$ and $2.94_{\mathrm{PAAS}}$. The ratios of $\mathrm{La}_{N} /$ $\mathrm{Sm}_{N}$ and $\mathrm{Gd}_{N} / \mathrm{Yb}_{N}$ are used to measure the degree of LREE fractionation and that of HREE fractionation, respectively. The degree of LREE fractionation with $\mathrm{La}_{N} / \mathrm{Sm}_{N}$ of

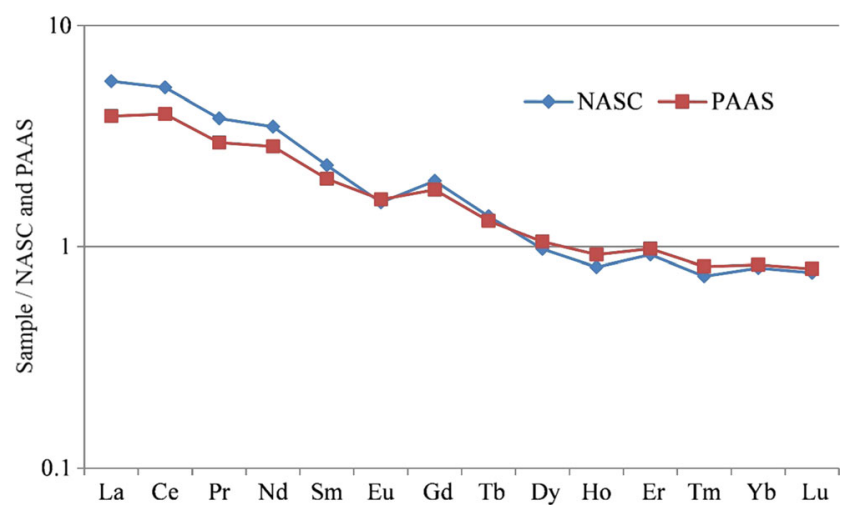

Fig. 5 NASC and PAAS normalized patterns of average REE concentrations in surface soils 
Table 2 NASC- and PASS-normalized patterns of REE concentrations in surface soils

\begin{tabular}{|c|c|c|c|c|c|c|c|c|c|c|c|c|c|}
\hline \multirow[t]{2}{*}{ LREE/HREE } & \multirow[t]{2}{*}{ LREE/ $\sum \mathrm{REE}$} & \multicolumn{2}{|c|}{$\mathrm{LREE}_{\mathrm{N}} / \mathrm{HREE}_{\mathrm{N}}$} & \multicolumn{2}{|c|}{$\mathrm{La}_{\mathrm{N}} / \mathrm{Yb}_{\mathrm{N}}$} & \multicolumn{2}{|c|}{$\mathrm{La}_{\mathrm{N}} / \mathrm{Sm}_{\mathrm{N}}$} & \multicolumn{2}{|c|}{$\mathrm{Gd}_{\mathrm{N}} / \mathrm{Yb}_{\mathrm{N}}$} & \multicolumn{2}{|l|}{$\delta \mathrm{Eu}$} & \multicolumn{2}{|l|}{$\delta \mathrm{Ce}$} \\
\hline & & NASC & PAAS & NASC & PAAS & NASC & PAAS & NASC & PAAS & NASC & PAAS & NASC & PAAS \\
\hline 27.32 & $95.51 \%$ & 3.93 & 2.94 & 6.97 & 4.70 & 2.48 & 2.18 & 2.39 & 1.92 & 0.73 & 0.85 & 1.12 & 1.26 \\
\hline
\end{tabular}

$2.48_{\text {NASC }}$ and 2.18 PAAS was slightly higher than that of HREE fractionation with $(\mathrm{Gd} / \mathrm{Yb})_{N}$ of $2.39_{\mathrm{NASC}}$ and $1.92_{\mathrm{PAAS}}$.

The depletion or enrichment of $\mathrm{Ce}$ and Eu usually occurred in the natural environment, which may be linked to their oxidation state and their mobility under different oxidationreduction conditions (Semhi et al. 2009). Ce exists in soils in both oxidation states, but under redox condition $\mathrm{Ce}^{3+}$ is more easily oxidized to $\mathrm{Ce}^{4+}$ with higher oxygen fugacity, which is much less mobile and results in positive Ce anomaly $(\delta \mathrm{Ce}>1)$. In the case of $\mathrm{Eu}$, it is an incompatible element in its trivalent form $\left(\mathrm{Eu}^{3+}\right)$ in an oxidizing magma and preferentially incorporated into plagioclase in its divalent form $\left(\mathrm{Eu}^{2+}\right)$ in a reducing magma, and this ion exchange process is the basis of the negative $\mathrm{Eu}$ anomaly $(\delta \mathrm{Eu}<1)$. In the present study, slight positive Ce anomaly with $\delta \mathrm{Ce}$ of $1.12_{\mathrm{NASC}}$ and $1.26_{\mathrm{PAAS}}$, and slight negative $\mathrm{Eu}$ anomaly with $\delta \mathrm{Eu}$ of $0.73_{\text {NASC }}$ and $0.85_{\text {PAAS }}$ were also observed, indicating that differentiation occurred between $\mathrm{Ce}, \mathrm{Eu}$, and other REEs in the weathering processes of parent rock.

\section{Conclusions}

Influenced by the exploitation of rare earth mineral, REEs in surface soils around the Bayan Obo Mine showed various levels of enrichment. The concentrations of total REE varied from 149.75 to $18,891.81 \mathrm{mg} \mathrm{kg}^{-1}$ with an average value of $1906.12 \mathrm{~m} \mathrm{~kg}^{-1}$. The order of the average concentrations of REEs in the surface soils around the Bayan Obo Mine area was as follows: $\mathrm{Ce}>\mathrm{La}>\mathrm{Nd}>\mathrm{Pr}>\mathrm{Sm}>\mathrm{Gd}>\mathrm{Dy}>\mathrm{Er}>\mathrm{Yb}$ $>\mathrm{Eu}>\mathrm{Tb}>\mathrm{Ho}>\mathrm{Tm}>\mathrm{Lu}$. The sequence was similar to that in Bayan Obo ores, which confirmed that the concentration and distribution of REEs were influenced by the mining activities. REE concentrations were higher in the vicinity of the eastern ore and western ore and decreased with the distance away from the center of the mining area. The spatial variability of REE concentrations in soils were strong in the mining area, which could be caused by the exploitation activities of REE resources and the strong northwesterly winds prevailed in this region. The concentrations of single REEs in the soil profiles showed a similar trend with depth, which increased at 0-25 cm section, then decreased and remained relatively constant in the deep part. The degree of LREE fractionation with $\mathrm{La}_{N} / \mathrm{Sm}_{N}$ of $2.48_{\text {NASC }}$ and $2.18_{\text {PAAS }}$ was slightly higher than that of HREE fractionation with $(\mathrm{Gd} / \mathrm{Yb})_{N}$ of $2.39_{\mathrm{NASC}}$ and
1.92 $\mathrm{PAAS}$. Slight positive Ce anomaly with $\delta \mathrm{Ce}$ of $1.12_{\mathrm{NASC}}$ and $1.26_{\mathrm{PAAS}}$, and slight negative Eu anomaly with $\delta \mathrm{Eu}$ of $0.73_{\text {NASC }}$ and $0.85_{\text {PAAS }}$ were also observed. The spatial distribution of REEs in soils showed a strong gradient concentration along the prevailing wind direction. The normalized curves inclined to the right side, showing the conspicuous fractionation between the light REEs and heavy REEs.

Acknowledgments This study was sponsored by the National Natural Scientific Foundation of China (nos. 41401591 and 41571473). Data presented in this paper are available by direct contact with the first author (wanglq@igsnrr.ac.cn).

\section{References}

Agnan Y, Séjalon-Delmas N, Probst A (2014) Origin and distribution of rare earth elements in various lichen and moss species over the last century in France. Sci Total Environ 487:1-12

Aguilar J, Dorronsoro C, Fernández E et al (2004) Soil pollution by a pyrite mine spill in Spain: evolution in time. Environ Pollut 132: 395-401

Anonymous (2012) Situation and policy of China's rare earth industry, White paper (English version). The State Council Information Office of the People's Republic of China (http://www.scio.gov.cn/ zfbps/ndhf/2012/Document/1175419/1175419.htm)

Aubert D, Stille P, Probst A et al (2002) Characterization and migration of atmospheric REE in soils and surface waters. Geochim Cosmochim Acta 66(19):3339-3350

Brioschi L, Steinmann M, Lucot E et al (2013) Transfer of rare earth elements (REE) from natural soil to plant systems: implications for the environmental availability of anthropogenic REE. Plant Soil 366:143-163

Cao XD, Wang XR, Zhao GW (2000) Assessment of the bioavailability of rare earth elements in soils by chemical fractionation and multiple regression analysis. Chemosphere 40:23-28

Chen Z (2011) Global rare earth resources and scenarios of future rare earth industry. J Rare Earths 29:1-6

Chen J, Yang R (2010) Analysis on REE geochemical characteristics of three types of REE-rich soil in Guizhou Province, China. J Rare Earth 28:517-522

CNEMC (China National Environmental Monitoring Center) (1990) The background concentrations of soil elements in China. Chinese Environment Science Press, Beijing (in Chinese)

Diatloff E, Asher CJ, Smith FW (1996) Concentrations of rare earth elements in some Australian soils. Aust J Soil Res 34:735-747

Drew LJ, Meng Q, Sun W (1990) The Bayan Obo iron-rare earth-niobium deposits, Inner Mongolia, China. Lithos 26:43-65

Hirano S, Suzuki KT (1996) Exposure, metabolism, and toxicity of rare earths and related compounds. Environ Health Perspect 104:85-95

Hu ZY, Haneklaus S, Sparovek G, Schnug E (2006) Rare earth elements in soils. Commun Soil Sci Plant Anal 37:1381-1420 
Jordens A, Cheng YP, Waters KE (2013) A review of the beneficiation of rare earth element bearing minerals. Miner Eng 41:97-114

Karanlik S, Aqca N, Yalcin M (2011) Spatial distribution of heavy metals content in soils of Amik plain (Hatay, Turkey). Environ Monit Assess 173:181-191

Laveuf C, Cornu S (2009) A review on the potentiality of rare earth elements to trace pedogenetic processes. Geoderma 154:1-12

Li JX, Hong M, Yin XQ et al (2010) Effects of the accumulation of the rare earth elements on soil macrofauna community. J Rare Earth 28: 957-964

Li X, Chen Z, Chen Z et al (2013) A human health risk assessment of rare earth elements in soil and vegetables from a mining area in Fujian Province, Southeast China. Chemosphere 93:1240-1246

Liang T, Li K, Wang L (2014) State of rare earth elements in different environmental components in mining areas of China. Environ Monit Assess 186:1499-1513

Loell M, Albrecht C, Felix-Henningsen P (2011) Rare earth elements and relation between their potential bioavailability and soil properties, Nidda catchment (Central Germany). Plant Soil 349:303-317

Loska K, Wiechuła D, Korus I (2004) Metal contamination of farming soils affected by industry. Environ Int 30:159-165

McGrath D, Zhang C, Carton OT (2004) Geostatistical analyses and hazard assessment on soil lead in silvermines area, Ireland. Environ Pollut 127:239-248

McLennan SM (2001) Relationships between the trace element composition of sedimentary rocks and upper continental crust. Geochem Geophys Geosyst 2:1021-1024

Morgan B, Rate AW, Burton ED et al (2012) Enrichment and fractionation of rare earth elements in FeS-and organic-rich estuarine sediments receiving acid sulfate soil drainage. Chem Geol 308:60-73

Pan X, Li DC, Peng A (2002) Application of rare-earth elements in the agriculture of China and its environmental behavior in soil. Environ Sci Pollut Res 9:143-148

Razo I, Carrizales L, Castro J et al (2004) Arsenic and heavy metal pollution of soil, water and sediments in a semi-arid climate mining area in Mexico. Water Air Soil Pollut 152(1-4):129-152

Salomons W (1995) Environmental impact of metals derived from mining activities: processes, predictions, prevention. J Geochem Explor $52: 5-23$

Semhi K, Chaudhuri S, Clauer N (2009) Fractionation of rare-earth elements in plants during experimental growth in varied clay substrates. Appl Geochem 24:447-453

Sen IS, Peucker-Ehrenbrink B (2012) Anthropogenic disturbance of element cycles at the earth's surface. Environ Sci Technol 46(16): 8601-8609
Sun J, Zhu X, Chen Y et al (2013) Iron isotopic constraints on the genesis of Bayan Obo ore deposit, Inner Mongolia, China. Precambrian Res $235: 88-106$

Sutherland RA (2000) Bed sediment-associated trace metals in an urban stream, Oahu, Hawaii. Environ Geol 39:611-27

Tan Q, Li J, Zeng X (2015) Rare earth elements recovery from waste fluorescent lamps: a review. Crit Rev Environ Sci Technol 45(7): 749-776

Tang W, Shan B, Zhang H et al (2010) Heavy metal sources and associated risk in response to agricultural intensification in the estuarine sediments of Chaohu Lake Valley, East China. J Hazard Mater 176: 945-951

Tyler G (2004) Rare earth elements in soil and plant systems - a review. Plant Soil 267:191-206

Wang HY, Wang DX, Wang YH et al (1995) Application of pattern recognition in a factor analysis - spectrophotometric method for the simultaneous determination of rare earth elements in geological sample. Analyst 5:1603-1608

Wang L, Liang T, Chong Z et al (2011) Effects of soil type on leaching and runoff transport of rare earth elements and phosphorous in laboratory experiments. Environ Sci Pollut Res 18:38-45

Wu C (2008) Bayan Obo controversy: carbonatites versus iron oxide-CuAu-(REE-U). Resour Geol 58:348-354

Xie Y, Li XW, Wang JF et al (2012) Spatial estimation of antibiotic residues in surface soils in a typical intensive vegetable cultivation area in China. Sci Total Environ 430:126-131

Xu C, Campbell IH, Kynicky J et al (2008) Comparison of the Daluxiang and Maoniuping carbonatitic REE deposits with Bayan Obo REE deposit, China. Lithos 106:12-24

$\mathrm{Xu}$ C, Taylor RN, Li W et al (2012) Comparison of fluorite geochemistry from REE deposits in the Panxi region and Bayan Obo, China. J Asian Earth Sci 57:76-89

Yoshida S, Muramatsu Y, Tagami K et al (1998) Concentrations of lanthanide elements, Th, and $\mathrm{U}$ in 77 Japanese surface soils. Environ Int 24:275-286

Yuan ZX, Bai G, Wu CY (1992) Geological features and genesis of the Bayan Obo REE ore deposit, Inner Mongolia, China. Appl Geochem 7:429-442

Zhang H, Feng J, Zhu WF et al (2000) Rare earth element distribution characteristics of biological chains in rare earth element-high background regions and their implications. Biol Trace Elem Res 73:1927

Zhu W, Kennedy M, De Leer EWB et al (1997) Distribution and modelling of rare earth elements in Chinese river sediments. Sci Total Environ 204:233-243 